\title{
Managing Water for Sustainable Utilization as China Warms
}

\author{
Guoqing Wang ${ }^{1,2 *}$ and Yueyang Wang ${ }^{3}$ \\ ${ }^{1}$ State Key Laboratory of Hydrology-Water Resources and Hydraulic Engineering, Nanjing Hydraulic Research Institute, China \\ ${ }^{2}$ Research Center for Climate Change, China \\ ${ }^{3}$ School of Geographical Sciences, Nanjing University of Information Science and Technology, China
}

Submission: January 25, 2019; Published: February 06, 2019

*Corresponding author: Guoqing Wang, State Key Laboratory of Hydrology-Water Resources and Hydraulic Engineering, Nanjing Hydraulic Research Institute and Research Center for Climate Change, Ministry of Water Resources, Nanjing, 210029, China

Abstract

Population growth, urbanisation and industrialisation are increasing demands and polluting sources of water. Climate change is one of several pressures on water resources in China. Although climate models agree warming will continue, rainfall projections are less certain. However, the prevailing pattern of 'north dry, south wet' looks set to persist, exacerbating water scarcity in some northern regions important for agriculture. As China's economy grows and competition for water intensifies, China will need to develop robust systems for managing water in an uncertain but increasingly volatile climate, particularly in the water-scarce north. This may require a new style of adaptive management, combining use of non-traditional sources such as urban waste water with better management of existing storage, and much more emphasis on water conservation and reallocation.

Keywords: Climate change; Water resources management; Adaptation

\section{Introduction}

In the next few decades, climate change in China will add pressure on water resources already under intense stress. China's successful investments in water-related infrastructure have helped mitigate climate variability and strengthen water, food and energy security; but the country's water supplies are now dwindling under a combination of population growth, rising per capita demand, urbanisation, industrialisation and pollution, particularly in the water-scarce north.

According to estimates of surface and groundwater flows, China has the world's sixth largest renewable water resources, roughly $2841 \mathrm{~km} 3 /$ year, but the water available per capita is only about $2151 \mathrm{~m} 3 /$ year, less than $30 \%$ of the global average [1]. Moreover, these scant water resources are unevenly distributed across the country and fluctuate dramatically over time. South and east China receive strong rains during the summer monsoon, raising their annual average rainfall to around $2,000 \mathrm{~mm} /$ year. Rainfall in the much drier west and north is less than one-fifth of this, only 200-400mm/year [2]. Regions with less than $1000 \mathrm{~m} 3$ rainfall per capita per year are commonly defined as 'water scarce' [3]; northern China has only $750 \mathrm{~m} 3$ per capita per year, less than one-fourth the rain per capita in the south and oneeleventh of the world average. With very limited water, the north nonetheless supports over $40 \%$ of the national population, has $60 \%$ of the arable land and generates over $40 \%$ of China's GDP.
The region produces roughly half of China's grain and nearly all its wheat and maize [4]. Rainfall in China also varies greatly from season to season and year to year, with a strong monsoonal influence. Droughts and floods are frequent, often occurring simultaneously in different regions. The Yangtze basin, for example, sees severe floods roughly once every 10 years, most recently in 1998, when flood water inundated 21 million ha of land and destroyed five million houses, causing an economic loss of over US $\$ 20$ billion [5]. Droughts, however, are responsible for the biggest economic losses and can devastate livelihoods in rural areas. A serious drought across five southwestern provinces in 2009-2010 affected roughly 7.7 million ha of farmland and left 24 million people and 15 million livestock struggling to access water. Direct economic losses, by late 2010, were estimated at US $\$ 3.6$ billion [6]. Climate change is likely to exacerbate these extreme events, increase the disparity between dry and wet regions, or alter seasonal patterns, and exacerbate these strains. It is therefore the water sector being one of four priority areas for adaptation identified in China's national climate change adaptation programme.

\section{Declining water resources in China: is climate change a cause?}

Across China as a whole, water resources have shrunk since the 1980s though some regions have dried less or become 
wetter. The World Bank estimates the cost of water scarcity and pollution at around 2.3\% of GDP [1]. Agriculture remains China's biggest water user, accounting for roughly $63 \%$ of withdrawals, mainly in the north [7]. This share is slowly declining as water conservation policies generate more 'crop per drop' and release water for fast-growing urban and industrial sectors. As combined demands rise, so does the production of wastewater and pollution, making clean water even scarcer.

It is challenging to untangle how much of the decline in water supply is due to rising demand and pollution, and how much to climate trends. These drivers were separated by using climate records, water consumption statistics and highresolution hydrological models [8]. China's climate overall has warmed since 1960 (by $1.2^{\circ} \mathrm{C}$ ); the northeast has warmed most, the southwest least. Country-wide precipitation over the same period has not changed significantly, but there are significant differences between the northeast (decreasing), the northwest (increasing) and the southeast (increasing) [9].

In the Yellow River basin in north China, with less rainfall and higher temperatures, river flows have fallen sharply over the last 40 years, particularly in the lower reaches of the basin (Figure 1). This reflects both climate trends and human activity, but increased withdrawals of water for irrigation, industry and domestic use are dominant, accounting for roughly $62 \%$ of the reduction in flow from the $1955-1970$ baseline [8]. In the Haihe basin in the northeast, one of China's most water-stressed, human activities are also the major cause of declining flows [10].

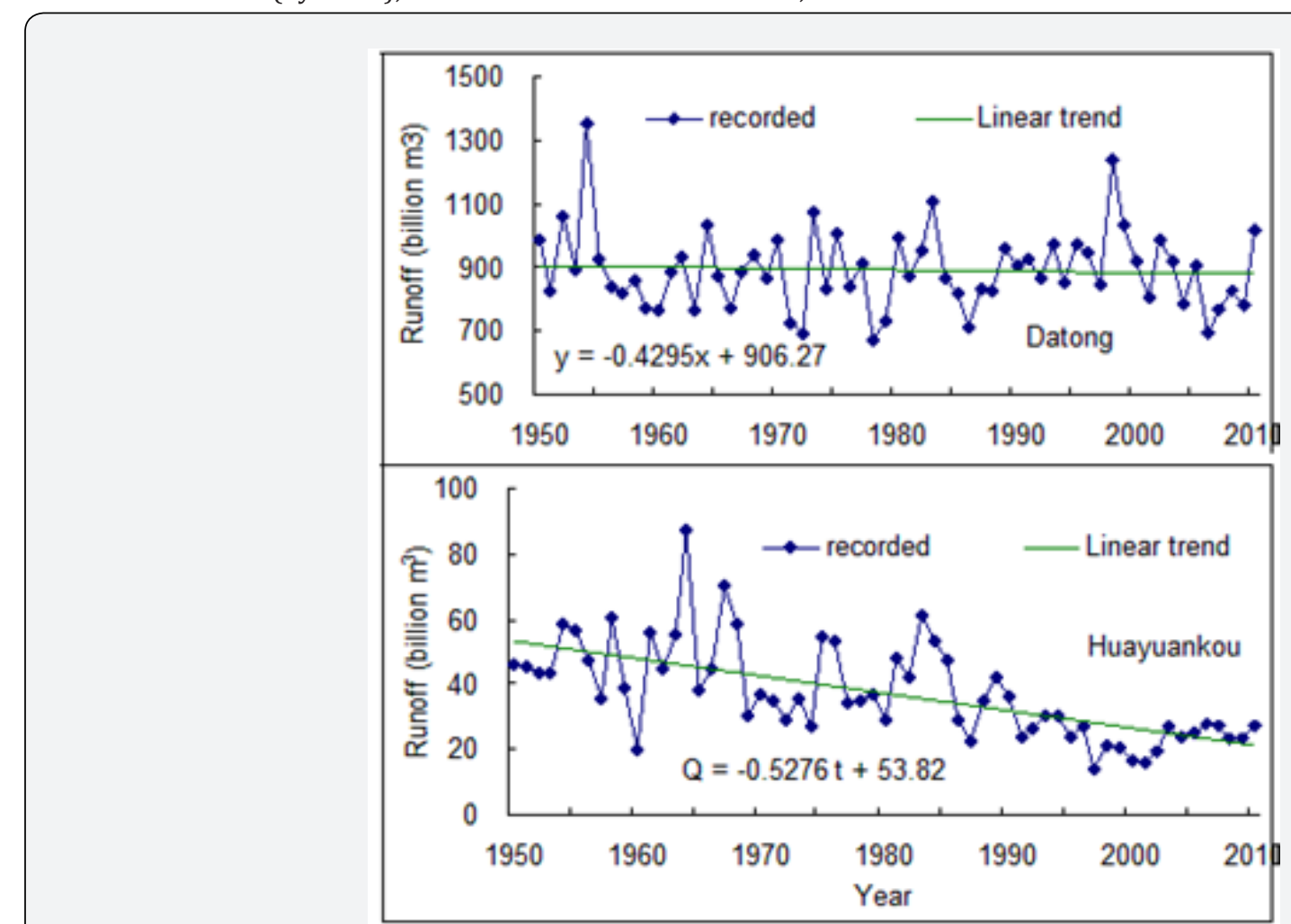

Figure 1: Observed inter-annual variation in annual river flow in the Yangtze (Datong station) and Yellow Rivers (Huayuankou station), China, 1950-2010.

Flows recorded at Datong in the lower Yangtze River show no marked trends in the period 1950-2010 (Figure 1). Flows have actually declined in the upper basin, due in part to less precipitation. In the middle and lower basin, however, increased precipitation and frequent rainstorms have swelled summer flows. A similar pattern is found in the Pearl River further south.

\section{China's future water supply under climate change}

Before now, assessments of future climate change in China have been based on the average of several Global Climate Models. These suggest that with medium levels of greenhouse gas emissions (a scenario known as $\mathrm{A} 1 \mathrm{~B}$ and RCP4.5), China's air temperature will rise by $0.27-0.32^{\circ} \mathrm{C} / 10$ a during $2021-2050$ and precipitation will increase by an average of $1.1-2.3$ by 2050 relative to 1961-1990, with more frequent heavy downpours. However, multi-model averages conceal significant variation, with different climate models projecting very different climate futures.

Using downscaled climate scenarios to drive hydrological models, we project how much runoff will be feeding Chinese rivers by mid-century. Whether future emissions are high, medium or low, annual runoff in the Yellow River basin of northcentral China - a key grain-producing area — declines by roughly 2.3-5.7\% from the period 1961-1990 to 2021-2050 with increasing risk of extreme events including flood and drought to some extent. For other river basins, the expected changes depend on the emissions scenario (Figure 2). In some cases, 
recent declines are projected to reverse: for example, the RCP4.5 scenario of GFDL-ESM2M and NORESM1-M leads to less flow in the northern, water-stressed Hai and Yellow River basins.

Particularly important for agriculture are changes during
June-September, the flooding and growing season. Trends for this period are similar but more pronounced. Hence, droughts affecting areas such as the Yellow River basin are most likely to hit during summer and harm crops, while other basins experience more intense summer rainfall and, potentially, flooding.

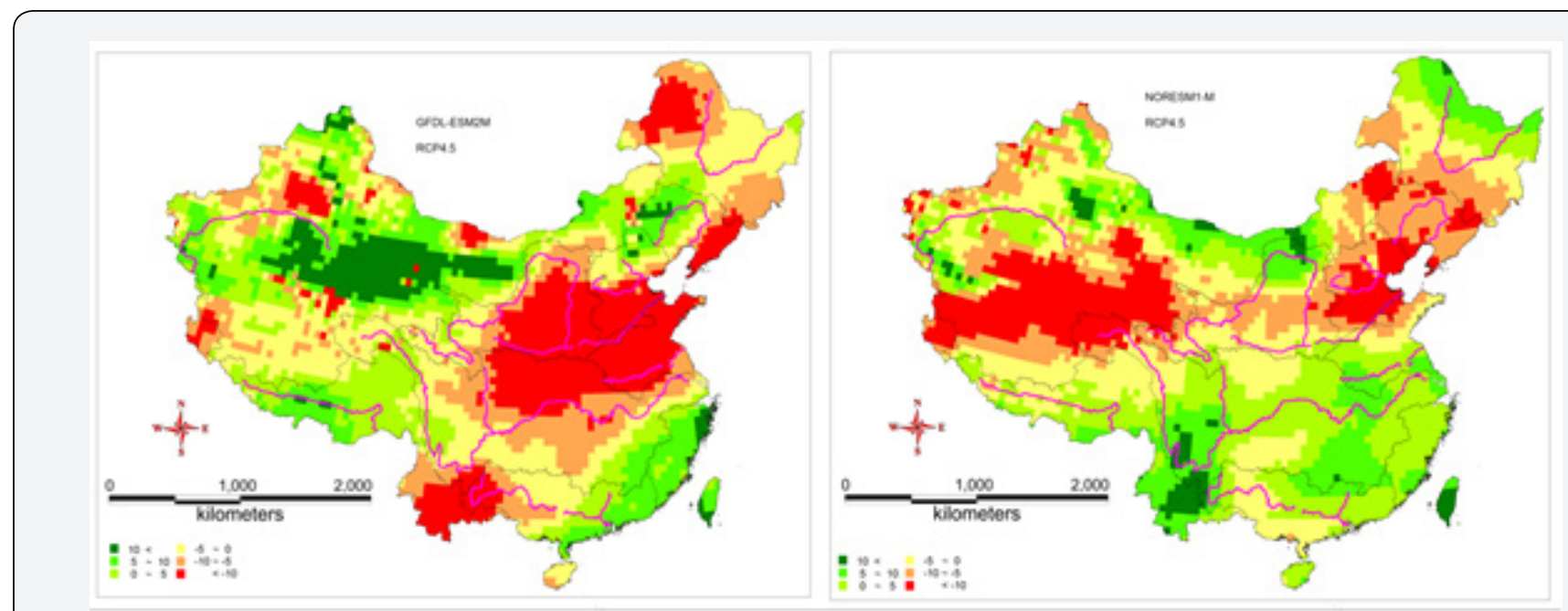

Figure 2: Changes in runoff (\%) from 1961-1990 to 2021-2050, based on GFDL-ESM2M (left) and NORESM1-M (right) under the scenarios RCP4.5 representing medium greenhouse gas emissions (Green indicates greatest increase in runoff, red indicates greatest decrease).

\section{Implications for adaptation planning}

As China's economy grows and competition for water increases, China will need to develop robust systems for managing water in an uncertain but increasingly volatile climate, particularly in the water-scarce north. Although changes in projected runoff remain uncertain for most basins, regional water shortages and regional flooding remain key issues that are likely to grow in importance as climate change amplifies existing patterns of shortage and excess. These pressures and uncertainties may require a new style of adaptive water management, combining use of non-traditional sources such as urban waste water with better management of existing storage, and much more emphasis on water conservation and reallocation. China's future measures to adapt to the coming changes should:

a) Understand the importance and irreversible impacts of climate change on water resources and incorporate the impacts of climate change into water resources assessment and planning.

b) Improve the repeated and circular utilization of water resources, enhance management of water demand and build a water-saving society.

c) In the most vulnerable regions, construct new water infrastructure, adopt strict water-conservation policies and maintain the capacity of water resources.

d) Diversify available water resources by increasing the use of unconventional sources. e) Develop better emergency response plans and improve institutions and capacity for emergency responses to extreme events.

f) Accelerate the development of the national water resources management and information system, to provide reliable information for management and decision-making.

g) Increase awareness of climate risks and adopt a new mindset on water resource management.

\section{Conclusions}

Declining flows in the Yellow and Haihe river basins are mostly due to human consumption, whereas climate change is already a major factor affecting the Yangtze and Pearl rivers. Different scenarios associated with different runoff changes. Under all emissions scenarios, annual runoff in the grain-rich Yellow River basin is expected to decline 2.3-5.7\%.

Climate change in China adds pressure on water resources already under stress, making the water sector a top priority in China's national adaptation programme. The most detailed climate impact projections to date call for aggressive measures to ensure China doesn't run dry.

\section{Acknowledgements}

This study has been financially supported by the National Key Research and Development Programs of China (Grants: 2016YFA0601501, 2016YFA0601601), the National Natural Science Foundation of China (Grants: 41830863, 51879162, 41601025), and State Key Laboratory of Hydrology-Water Resources and Hydraulic Engineering (Grant No. 2017490211). 
Many thanks also go to Prof. Ying Xu from China Meteorological Administration for providing climate scenarios.

\section{References}

1. World Bank (2007) Cost of Pollution in China. Economic Estimates of Physical Damages (Conference edition). World Bank, Washington D.C, USA.

2. Zhang HL (2005) Strategy study for water management in China. Southeast University Press, Nanjing, China.

3. Falkenmark M (1989) The massive water scarcity threatening Africa why isn't it being addressed? Ambio 18(2): 1112-1118.

4. Zhang JY, Wang GQ (2007) Impacts of Climate Change on Hydrology and Water Resources. Science Press, Beijing, China.

5. Zong YQ Chen XQ (2000) The 1998 flood on the Yangtze, China. Natural Hazards 22(2): 165-184.
6. Ministry of Civil Affairs (MCA) (2010) Reports of drought status and control measures. MCA, People's Republic of China.

7. Ministry of Water Resources (MWR) (2013) Annual Report 20112012. Ministry of Water Resources, People's Republic of China.

8. Wang GQ Zhang JY, Yang QL (2016) Attribution of Runoff Change for the Xinshui River Catchment on the Loess Plateau of China in a Changing Environment. Water 8(6): 267.

9. Compilation Commission of China's National Assessment for Climate Chang (CCCNACC) (2015) The Third China's National Assessment for Climate Change [M]. Beijing, Science Press, China.

10. Bao ZX, Zhang JY, Wang GQ Fu GB, He RM, et al. (2012) Attribution for decreasing streamflow of the Haihe River basin, northern China: Climate variability or human activities? Journal of Hydrology 460: 117129.

Your next submission with Juniper Publishers will reach you the below assets

- Quality Editorial service

- Swift Peer Review

- Reprints availability

- E-prints Service

- Manuscript Podcast for convenient understanding

- Global attainment for your research

- Manuscript accessibility in different formats ( Pdf, E-pub, Full Text, Audio)

- Unceasing customer service

Track the below URL for one-step submission https://juniperpublishers.com/online-submission.php 